\title{
Vascular endothelium, cytokines, and the pathogenesis of inflammatory synovitis
}

\author{
Arvind Kaul, David R Blake, Jeremy D Pearson
}

In the past 15 years, primarily as a direct consequence of the ability to isolate and culture vascular endothelial cells routinely, it has become obvious that the endothelium does not function simply as a selective permeability barrier. Endothelial cells are now known to contribute directly to the control of many aspects of vascular homeostasis, including the processes of blood coagulation and fibrinolysis, platelet activation, vasomotor tone and vascular permeability, vessel growth and remodelling, and leucocyte trafficking under normal and pathological conditions. ${ }^{1}$

The most obvious changes in the inflamed rheumatoid joint that may reflect endothelial cell dysfunction include increased fluid and protein leakage into the tissue, coupled with leucocyte accumulation, and in the longer term, altered capillary density and anatomy in the hyperplastic synovium. ${ }^{2}$ A recent review article in this journal discussed the possible role of hypoxic reperfusion injury in relation to endothelial cell pathology and joint damage. ${ }^{3}$ Here we review the recent advances in another area of endothelial cell biology-namely, the dramatic changes in endothelial cell function brought about by the action of specific cytokines or bacterial lipopolysaccharides, and how these changes may relate to pathogenesis in the joint, in paticular by upregulating the ability of endothelial cells to support leucocyte traffic into the synovium.

\section{Endothelial cell activation}

Endothelial cells undergo morphological and functional changes at the sites of cell mediated immune and inflammatory reactions. These changes have been described as activation ${ }^{4}$ and can include proliferation, accumulation of intracellular organelles, hypertrophy, and increased matrix deposition. More recently, Pober $^{5}$ defined endothelial cell activation as a quantitative change in the levels of expression of several specific gene products, which allows the cells to perform new functions. These include enhanced adhesion of specific leucocyte classes owing to the expression of surface glycoproteins, which is discussed in more detail below, and other alterations in cell function related to the control of vascular tone, platelet function, and blood coagulation. $^{6}$

Leucocyte accumulation in vivo, in response to injection of supernatants from stimulated lymphocyte cultures, was first demonstrated by Dumonde et al. ${ }^{7}$ Enhanced lymphocyte adhesion to endothelial cells in vitro in response to such supernatants, known to contain lymphocyte stimulatory molecules (lymphokines), was first reported by De Bono. ${ }^{8}$ Purified proteins from these mixtures, now known as cytokines since they act on many cell types other than lymphocytes, have subsequently been shown to act singly or in combination on endothelial cells to upregulate leucocyte adhesion. Thus interleukin 1 enhances neutrophil and lymphocyte adhesion with different time courses, whereas interferon $\gamma$ enhances only lymphocyte adhesion. ${ }^{9-11}$

\section{Neutrophil-endothelial cell adhesion mechanisms}

The initial recruitment of neutrophils to an inflammatory site is primarily dependent on chemotactic factors generated in the tissue, such as the activated complement fragment $\mathrm{C} 5 \mathrm{a}$, leukotriene $\mathrm{B}_{4}$, or platelet activating factor. Neutrophils or monocytes stimulated by chemotactic agents, whether generated exogenously or presented by the endothelial cells, transiently show enhanced adhesion to endothelium. ${ }^{12-14}$ Longer term regulation of neutrophil adhesion to endothelial cells, particularly over periods of hours rather than minutes, is brought about by the induction of endothelial protein synthesis in response to cytokines.

ELAM-1 has recently been identified and characterised as an inducible surface glycoprotein that is important for neutrophil adhesion. Basal expression is undetectable, but when endothelial cells are exposed in vitro to interleukin 1, tumour necrosis factor, bacterial lipopolysaccharide, or lymphotoxin ELAM-1 expression is found after one to two hours, peaks at about six hours, and declines towards zero by 24 hours. $^{10} 1516$ Experiments with a blocking monoclonal antibody to ELAM-1 confirmed that the increased neutrophil adhesion, which is temporally correlated with ELAM-1 expression, was significantly inhibited, ${ }^{17}$ and transfection of ELAM-1 cDNA into COS cells showed that expression of this molecule at the cell surface was sufficient to induce neutrophil adhesion. ${ }^{18}$

ELAM-1 is also expressed on endothelial cells in vivo in response to the induction of delayed hypersensitivity reactions, ${ }^{19} 20$ and in skin explant cultures after stimulation of mast cell degranulation, where the activator appears to be tumour necrosis factor. ${ }^{21}$ Interestingly, the in vivo expression of ELAM-1 was more prolonged (still strongly positive at 24 hours) than occurs in vitro. The presence of ELAM-1 on endothelium in rheumatoid synovium has been reported in a recent abstract ${ }^{22}$; and in preliminary experiments we detected ELAM-1 by immunofluorescence on a proportion of endothelial cells 
in synovial samples from patients with rheumatoid arthritis but not from those with osteoarthritis (Kaul A, unpublished observations).

On the neutrophil a member of the integrin family of adhesive ligands, CD11b/CD18, is essential for neutrophil adhesion and emigration in vitro and in vivo. ${ }^{23} \mathrm{CD} 11 \mathrm{~b} / \mathrm{CD} 18$ does not interact with ELAM-1, but with intercellular adhesion molecule-1 (ICAM-1) and ICAM-2 molecules present on non-activated endothelial cells. $^{24} 25$ ICAM-1 expression increases on cytokine activated endothelium, but with a slower time course that more closely correlates with enhanced lymphocyte adhesion (see below). As yet, the neutrophil receptor for ELAM-1 has not been identified. In addition, Dobrina et al have provided evidence that part of the adhesion of neutrophils to stimulated endothelium is independent of ELAM-1, ${ }^{26}$ suggesting that other molecules are involved. One candidate is GMP140: this molecule, rapidly translocated to the surface of endothelial cells in response to thrombin or histamine, where it transiently upregulates neutrophil adhesion, has also been implicated recently in adhesion to endothelial cells stimulated by lipopolysaccharide..$^{27} 28$

Further long term regulation of neutrophil recruitment to inflammatory sites may occur as a result of cytokine induced synthesis and secretion of other proteins by endothelium. These include colony stimulating factors that can act on bone marrow to accelerate myeloid cell production and release. ${ }^{29}$ In addition, endothelial cells stimulated by lipopolysaccharide or cytokine release interleukin 8 related molecules, which are potent chemotactic agents for neutrophils and monocytes. ${ }^{30}$ Gimbrone et al have recently identified as interleukin 8 an endothelial mediator that downregulates neutrophil adhesion to activated endothelial cells. ${ }^{31}$ This is likely to be an example of a phenomenon common to all neutrophil chemotactic agents, whereby long term exposure desensitises neutrophil responsiveness, and it may be relevant in vivo to the temporal control of neutrophil emigration.

\section{Lymphocyte-endothelial cell adhesion mechanisms}

Normal lymphocyte traffic-that is, recirculation between the bloodstream and lymphoid tissues, occurs by specific adhesive interactions between specialised postcapillary venules, lined by large columnar endothelial cells that are histochemically distinct from the flattened endothelial cells elsewhere. ${ }^{32}$ Unlike endothelial cells in most normal vessels these 'high' endothelial cells (HEC) express readily detectable levels of class II major histocompatibility complex (MHC) antigens. ${ }^{33}$ Morphologically similar HEC develop in chronic inflammatory lesions in a variety of diseases, including rheumatoid arthritis, Sjögren's syndrome, and within tumours, where lymphocyte infiltration is evident. ${ }^{34-36}$ These studies, together with the sparseness of HEC in athymic mice, ${ }^{37}$ indicate that the morphological changes are a consequence of the secretion of lymphocyte products, which perhaps in turn lead to phenotypic alterations in endothelial function that enhance lymphocyte accumulation.
Normal lymphocyte subclasses vary in their ability to bind to HEC from different lymphoid organs. Thus B cells bind preferentially to HEC in gut associated lymphoid tissue, where $\mathrm{T}$ cells bind preferentially to peripheral lymph node HEC. ${ }^{38}$ Furthermore, some lymphoma cell lines bind almost exclusively to HEC in one or the other tissue. ${ }^{39}$ This suggests that lymphocytes and HEC express organ specific receptorligand pairs to regulate the homing patterns observed. In humans, homing receptors on the lymphocyte surface are defined by the Hermes series of monoclonal antibodies. ${ }^{40}$ These bind to 'addressin' molecules on HEC. Several addressins have been defined in mouse and man and shown to be induced by interferon $\gamma .{ }^{41} 42$ The human addressin identified by monoclonal antibody HECA-452 is found in organised lymphoid tissue and at certain chronic inflammatory sites, including synovial HEC. ${ }^{43}$ Some antibodies that block lymphocyte binding to HEC in lymphoid tissue do not inhibit adhesion to HEC in inflamed synovium. ${ }^{44}$ It therefore remains an open question whether as yet undefined addressins are expressed in rheumatoid synovium. A selective adhesion mechanism is suggested by the greater ability of some lymphocytes with a preference for gut associated normal lymphoid tissue to adhere to HEC in inflamed synovium. This is also consistent with the clinical link between inflammatory bowel disease and synovitis, and the possibility of shared antigenic stimuli-for example, yersinial or mycobacterial products. ${ }^{45}$ Nonetheless, a major influence on lymphocyte infiltration and accumulation in the inflamed joint is likely to be the local expression of tissue non-selective endothelial cell surface adhesive molecules in response to cytokines, as discussed below.

In vitro experiments suggest that the induction of increased lymphocyte adhesion to endothelium in response to cytokines is slower and longer lasting than for neutrophils, with a maximum after about 24 hours. ${ }^{6}$ This correlates well with increased levels of ICAM-1 expression on endothelial cells, which peak at $>10$-fold higher than basal levels. ${ }^{46}$ ICAM-1 and ICAM-2 are each ligands for the lymphocyte adhesion molecule CDIla/CD18 (lymphocyte function associated antigen-1 (LFA-1)). ${ }^{24}$ Increased endothelial ICAM-1 expression is also found in vivo at sites of delayed hypersensitivity reactions or after tumour necrosis factor and interferon $\gamma$ injection, ${ }^{2047}$ and its physiological expression on endothelium is more intense in $\mathrm{T}$ cell dependent areas of lymph nodes. ${ }^{48}$ In addition to the cytokines mentioned previously, interferon $\gamma$ enhances lymphocyte adhesion and ICAM-1 expression in vitro, though it does not upregulate neutrophil adhesion. ${ }^{94}$ Uniquely, interferon $\gamma$ also induces the expression of MHC class II molecules on the surface of endothelial cells in vitro, ${ }^{49} 50$ which, as noted above, are present on HEC.

Blocking antibodies to $\mathrm{CD} 1 \mathrm{la} / \mathrm{CD} 18$ significantly inhibit the adhesion of lymphocytes to unstimulated endothelial cells but only weakly inhibit lymphocyte adhesion to activated endothelial cells. ${ }^{51}$ Also, patients in whom all leucocytes lack CD11/CD18 show severely impaired 
neutrophil adhesion and emigration but apparently normal lymphocyte recruitment to inflammatory sites. ${ }^{25} 52$ Thus mechanisms independent of ICAM-1 must play a part in lymphocyte adhesion and emigration. Two studies have indicated that MHC class II molecules may be involved. ${ }^{53}{ }^{54}$ In addition, the surface glycoprotein VCAM-1 (vascular cell adhesion molecule-1) has been implicated as one such molecule, ${ }^{55}$ and it may be involved in the ICAM-1 independent stimulated adhesion of T cells found when endothelial cells are exposed to interleukin $4 .^{56}$ The lymphocyte receptor for VCAM-1 is now known to be the integrin VLA $-4,{ }^{57}$ and antibodies to either VLA-4 or VCAM-1 reduce lymphocyte adhesion to endothelial cells. ${ }^{58}$

The discovery that endothelial cells express MHC class II antigens in response to interferon $\gamma$ led to the finding that endothelial cells activated in this way in vitro efficiently present antigen to primed $T$ cells and cause $T$ cell proliferation. 5960 The mechanisms by which this occurs might include the stimulated synthesis and secretion of interleukin 6 by endothelium $^{61}$ (which helps $T$ cells to secrete interleukin 2, a lymphocyte mitogen), though smooth muscle cells and fibroblasts can also be stimulated by interferon $\gamma$ to express class II molecules and release interleukin 6 , but they do not support lymphocyte proliferation. ${ }^{62}$ Recently, an additional endothelial cell-specific mechanism, requiring cell contact between lymphocytes and endothelium and involving lymphocyte $\mathrm{CD} 2$ surface molecules, has been described. ${ }^{63}$

\section{Cytokines and rheumatoid arthritis}

Until recently, evidence about the presence of cytokines in synovial tissue or fluid has been confusing, with variable results depending on the type of assay used. The situation has become somewhat clearer with the realisation that inhibitors of the activity of cytokines may be concomitantly present in vivo, though they may not be locally generated as synovial cultures synthesise substantial amounts of several cytokines. ${ }^{64}$ Thus the presence of interleukin 1 in synovial fluid from patients with rheumatoid arthritis is more easily detectable by immunoassays than bioassays, ${ }^{65}$ but interleukin 1 activity is found in culture supernatants from rheumatoid synovium ${ }^{66}$ and interleukin $1 \mathrm{mRNA}$ is present in synovial tissue. ${ }^{67}$ Interestingly, in cultured synovium interleukin 1 concentrations correlated well with the extent of vascularity and with MHC class II antigen expression on synoviocytes and endothelium. ${ }^{66}$ Tumour necrosis factor protein has also been detected in synovial tissue and fluid from rheumatoid patients. ${ }^{64}$ Interleukin 6, which is abundantly produced by endothelial cells activated in vitro, ${ }^{61}$ is also present in excess in rheumatoid synovial fluid. ${ }^{68}$

In contrast, surprisingly little interferon $\gamma$ is found in synovial fluid or produced by explants of rheumatoid synovium, ${ }^{69}$ despite the presence of class II antigens, whose induction is presumed to be due to interferon $\gamma$. This lack of interferon $\gamma$ correlated with a relative lack of other detectable $\mathrm{T}$ cell derived cytokines (interleukins 2 and 3), ${ }^{70}{ }^{71}$ and perhaps implies that $T$ cells in the inflamed synovium are in some way inhibited from synthesising cytokines.

\section{Conclusion}

The experimental evidence summarised above indicates that cytokines activate endothelial cells in ways that lead to leucocyte accumulation and emigration into tissues. Thus although endothelium has not yet been ascribed a role in the initiation of inflammatory synovitis, it is likely to be intimately involved in the regulation of disease progression and pathogenesis, and particularly to cooperate in the process of leucocyte recruitment. Further work is urgently needed to define more closely the presence and consequences of activated endothelium in rheumatoid synovium. The rapidly emerging power of molecular biological techniques to detect and localise the sites of synthesis and action of cytokines will contribute greatly to this. A further valuable aid will be the availability of microvascular endothelial cells from rheumatoid synovium, the successful culture of which has very recently been reported, ${ }^{72}$ and we have found the technique to be reproducible. Although we feel that insufficient thought has been given as yet to designing in vitro experiments under conditions that more closely mimic the environment of the diseased synoviumthat is, hypoxia and acidosis, ${ }^{3}$ we are confident that significant progress in this area, linking the advances in our understanding of basic endothelial cell biology to the elucidation of the pathogenesis of rheumatoid synovium, will be made in the near future.

We thank the Arthritis and Rheumatism Council for financial support for studies relating to the inflammation research group discussed in this review.

1 Petty R G, Pearson J D. Endothelium-the axis of vascular health and disease. F $R$ Coll Physicians 1989; 23: 92-102.

2 Stevens C R, Revell P A, Blake D R, Levick J R. Synovia vascular morphometry suggests that a state of chronic hypoxia exists in rheumatoid joints. $B r \mathcal{F}$ Rheumatol 1989; 28 (suppl 2): 62.

3 Stevens C R, Williams R B, Farrell A J, Blake D R. Hypoxia and inflammatory synovitis: observations and speculations. Ann Rheum Dis 1991; 50: 124-32.

4 Clark R A F, Dvorak H F, Colvin R B. Fibronectin in delayed-type hypersensitivity reactions: associations with vessel permeability and endothelial cell activation. f Immunol 1981; 126: 787-93.

5 Pober J S. Cytokine-mediated activation of vascular endothelium: physiology and pathology. Am f Pathol 1988; 133: 426-33.

6 Pober J S, Cotran R S. Cytokines and endothelial cell biology. Physiol Rev 1990; 70: 427-51.

7 Dumonde D C, Pulley M S, Paradinas F J, et al. Histological features of skin reactions to human lymphoid cell lymphokine in patients with advanced cancer. $\mathcal{F}$ Pathol 1982; 137 289-308.

8 De Bono D. Endothelium-lymphocyte interactions in vitro. II Adherence of allergized lymphocytes. Cell Immunol 1979; 44: 64-70.

9 Yu C-L, Haskard D O, Johnson A R, Ziff M. Human $\gamma$ interferon increases binding of $T$ lymphocytes to endothelial cells. Clin Exp Immunol 1985; 62: 554-60.

10 Bevilacqua M P, Pober J S, Wheeler M E, Cotran R S, Gimbrone $M$ A. Interleukin-1 acts on cultured human vascular endothelium to increase the adhesion of polymorphonuclear leukocytes, monocytes and related leukocytic cell lines. $\mathrm{f}$ Clin Invest 1985; 76: 2003-11.

11 Cavender D E, Haskard D O, Joseph B, Ziff M. Interleukin-1 increases the binding of $B$ and $T$ lymphocytes to endothelial cell monolayers. F Immunol 1986; 136: 203-7. 
12 Doherty D E, Haslett C, Tonnesen M G, Henson P M. Human monocyte adherence: a primary effect of chemotactic factors on the monocyte to stimulate adherence to human endothelium. F Immunol 1987; 138: 1762-71.

13 Tonnesen M G. Neutrophil-endothelial cell interactions: mechanisms of neutrophil adherence to vascular endothelium. F Invest Dermatol 1989; 93: 53S-8S.

14 Zimmerman G A, MacIntyre T M, Mehra M, Prescott S M. Endothelial cell-associated platelet-activating factor: a novel mechanism for signalling intracellular adhesion. $\mathcal{F} \mathrm{Cell}$ Biol 1990; 110: 529-40.

15 Pober J S, Lapierre L A, Stolpen A H, et al. Activation of cultured human endothelial cells by recombinant lymphotoxin: comparison with tumor necrosis factor and interleukin 1 species. F Immunol 1987; 138: 3319-24.

16 Pohlman T H, Stanness K A, Beatty P G, Ochs H D, Harlan J M. An endothelial cell surface factor induced in vitro by lipopolysaccharide, interleukin 1 or tumor necrosis factor-0 increases neutrophil adherence by a CDw18-dependent mechanism. F Immunol 1986; 136: 4548-53.

17 Bevilacqua M P, Pober J S, Mendrick D L, Cotran R S, Gimbrone M A. Identification of an inducible endothelialleukocyte adhesion molecule. Proc Natl Acad Sci USA 1987; 84: 9238-42.

18 Bevilacqua M P, Stengelin S, Gimbrone M A. Endothelial leukocyte adhesion molecule 1 : an inducible receptor for neutrophils related to complement regulatory proteins and lectins. Science 1989; 243: 1160-5.

19 Cotran R S, Gimbrone M A, Bevilacqua M P, Mendrick D L, Pober J S. Induction and detection of a human endothelial activation antigen in vivo. $\mathcal{F}$ Exp Med 1986; 164: 661-6.

20 Norris P G, Thomas S, Poston R, Hawk J L M, Haskard D O Expression of endothelial leukocyte adhesion molecule-1 and intercellular adhesion molecule-1 in the evolution of cutaneous inflammation: a comparison of ultraviolet- $B$ erythema and delayed type hypersensitivity. $\mathrm{Br} \mathcal{F}$ Dermatol 1990; 122: 274-5.

21 Klein L M, Lavker R M, Matis W L, Murphy G F. Degranulation of human mast cells induces an endothelial antigen central to leukocyte adhesion. Proc Natl Acad Sci USA 1989; 86: 8972-6.

22 Corkill M M, Kirkham B W, Barbatis C, Haskard D O, Gibson T, Panayi G. Changes in synovial membrane endothelial adhesion receptor expression following treatment of rheumatoid arthritis [abstract]. Br $\mathcal{F}$ Rheumatol 1989; 28 (suppl 2): 66.

23 Carlos T M, Harlan J M. Membrane proteins involved in phagocyte adherence to endothelium. Immunol Rev 1990; 114: 5-27.

24 Staunton DE, Dustin M L, Springer T A. Functional cloning of ICAM-2, a cell adhesion ligand for LFA-1 homologous to ICAM-1. Nature 1989; 339: 61-4.

25 Dustin M L, Springer T A. Lymphocyte function associated antigen-1 interaction with intercellular adhesion molecule-1 is one of at least three mechanisms for lymphocyte adhesion to cultured endothelial cells. $\mathcal{F}$ Cell Biol 1988; 107: 321-31.

26 Dobrina A, Schwartz B R, Carlos T M, Ochs H D, Beatty P G, Harlan J M. CD11/CD18-independent neutrophil adherence to inducible endothelial-leukocyte adhesion molecules in vitro. Immunology 1989; 67: 502-8.

27 Geng J G, Bevilacqua M P, Moore K L, et al. Rapid neutrophil adhesion to activated endothelium mediated by GMP-140. Nature 1990; 343: 757-60.

28 Toothill V J, Van Mourik J A, Niewenhuis H K, Metzelaar $M J$, Pearson J D. Characterisation of the enhanced adhesion of neutrophil leukocytes to thrombin-stimulated endothelial cells. F Immunol 1990; 145: 283-91.

29 Zsebo K M, Yuschenkoff V N, Schiffer S, et al. Vascular endothelial cells and granulopoiesis: interleukin-1 stimulates release of G-CSF and GM-CSF. Blood 1988; 71:99-103.

30 Strieter R M, Kunkel S L, Showell H J, et al. Endothelial cell gene expression of a neutrophil chemotactic factor by TNF- $\alpha$, LPS and IL-1 $\beta$. Science 1989; 243: 1467-9.

31 Gimbrone M A, Obin M S, Brock A F, et al. Endothelial interleukin-8: a novel inhibitor of leukocyte-endothelial interactions. Science 1989; 246: 1601-3.

32 Marchesi V T, Gowans J L. The migration of lymphocytes through the endothelium of venules in lymph nodes: an electron microscope study. Proc Roy Soc Biol 1964; 159: 283-90.

33 Turner R R, Beckstead J H, Warnke R A, Wood G S. Endothelial cell phenotypic diversity. In situ demonstration of immunologic and enzymatic heterogeneity that correlate with specific morphologic subtypes. Am $\mathcal{F}$ Clin Pathol 1987; 87: 569-75.

34 Freemont A J. The small blood vessels in areas of lymphocytic infiltration around malignant neoplasms. Brf Cancer 1982; 46: 283-8.

35 Freemont A J, Jones C J P. Endothelial specialization of salivary gland vessels for accelerated lymphocyte transfer in Sjögren's syndrome. $\mathcal{F}$ R heumatol 1983; 10: 801-4.

36 Freemont A J, Jones C J P, Bromley M, Andrews P. Changes in vascular endothelium related to lymphocyte collections in diseased synovia. Arthritis Rheum 1983; 26: 1427-33.

37 De Sousa M A, Parrott D M V, Pantelouris E M. The lymphoid tissues in mice with congenital aplasia of the thymus. Clin Exp Immunol 1969; 4: 637-44.

38 Pals S T, Kraal G, Horst E, Groot A, Scheper R J, Meijer C J L M. Human lymphocyte-high endothelial venule interaction: organ-selective binding of $\mathrm{T}$ and $\mathrm{B}$ lymphocyte populations to high endothelium. I Immunol 1986; 137: $760-63$.

39 Bargatze R F, Wu N W, Weissman I L, Butcher E C. High endothelial venule binding as a predictor of the dissemination of passaged murine lymphomas. $\mathcal{F}$ Exp Med 1987; 166: 1125-31.

40 Jalkanen S T, Bargatze R F, Herron L R, Butcher E C A lymphoid cell surface glycoprotein involved in endothelial cell recognition and lymphocyte homing in man. Eur f Immunol 1986; 16: 1195-202.

41 Duijvestin A M, Kerkhove M, Bargatze R F, Butcher E C. Lymphoid tissue- and inflammation-specific endothelial cell differentiation defined by monoclonal antibodies. $\mathcal{I}$ Immunol 1987; 138: 713-9.

42 Duijvestijn A M, Horst E, Pals S T, et al. High endothelial differentiation in human lymphoid and inflammatory tissues defined by monoclonal antibody HECA-452. Am $\mathcal{F}$ Pathol 1988; 130: 147-55.

43 Van Dinther-Janssen A C H M, Pals S T, Scheper R, Breedveld F, Meijer C J L M. Dendritic cells and high endothelial venules in the rheumatoid synovial membrane. f Rheumatol 1990; 17: 11-17.

44 Jalkanen S, Steere A C, Fox R I, Butcher E C. A distinct endothelial cell recognition system that controls lymphocyte traffic into inflamed synovium. Science $1986 ; 233$ : 556-8.

45 Jalkanen S. Leukocyte-endothelial cell interaction and the control of leukocyte migration into inflamed synovium. Springer Semin Immunopathol 1989; 11: 187-98.

46 Pober I S, Gimbrone M A, Lapierre L A, et al. Overlapping patterns of activation of human endothelial cells by interleukin-1, tumour necrosis factor, and immune interferon. F Immunol 1986; 137: 1893-6.

47 Munro J M, Pober J S, Cotran R S. Tumor necrosis factor and interferon $\gamma$ induce distinct patterns of endothelial activation and associated leukocyte accumulation in skin of Papio anubis. Am f Pathol 1989; 135: 121-33.

48 Dustin M L, Rothlein R, Bhan A K, Dinarello C A, Springer T A. Induction by IL- 1 and interferon $\gamma$; tissue distribution, biochemistry and function of a natural adherence molecule (ICAM-1). F Immunol 1986; 137: 245-54.

49 Groenewegen G, Buurman W A, van der Linden C J. Lymphokine dependence of in vivo expression of MHC class II antigens by endothelium. Nature 1985; 316: 361-3.

50 Pober J S, Gimbrone M A, Cotran R S, et al. Ia expression by vascular endothelium is inducible by activated $T$ cells and by human $\gamma$-interferon. 7 Exp Med 1983; 157: 1339-53.

51 Haskard D, Cavender D, Beatty P, Springer T, Ziff $M$. $T$ lymphocyte adhesion to endothelial cells: mechanisms demonstrated by anti-LFA-1 monoclonal antibodies. I Immunol 1986; 137: 2901-6.

52 Osborn L. Leukocyte adhesion to endothelium in inflammation. Cell 1990; 62: 3-6.

53 Masuyama J, Minato N, Kano S. Mechanisms of lymphocyte adhesion to human vascular endothelial cells in culture. T lymphocyte adhesion to endothelial cells through endothelial HLA-DR antigens induced by gamma interferon. $\mathcal{f}$ Clin Invest 1986; 77: 1596-605.

54 Thornhill M H, Williams D M, Speight P M. Enhanced adhesion of autologous lymphocytes to gamma interferontreated human endothelial cells in vitro. Br $\mathcal{F}$ Exp Pathol 1989; 70: 59-64.

55 Osborn L, Hession C, Tizard R, et al. Direct cloning of vascular cell adhesion-molecule 1 , a cytokine-induced protein that binds to lymphocytes. Cell 1989; 59: 1203-11.

56 Thornhill M H, Kyan-Aung U, Haskard D O. IL-4 increases human endothelial cell adhesiveness for $\mathrm{T}$ cells but not for neutrophils. F Immunol 1990; 144: 3060-5.

57 Elices M J, Osborn L, Takada Y, et al. VCAM-1 on activated endothelium interacts with the leukocyte integrin VLA-4 at a site distinct from the VLA4/fibronectin binding site. Cell 1990; 60: 577-84.

58 Schwartz B R, Wayner E A, Carlos T M, Ochs H D, Harlan $J$ M. Identification of surface proteins mediating adherence of CD11/CD18-deficient lymphoblastoid cells to cultured endothelium. F Clin Invest 1990; 85: 2019-22.

59 Ashida E R, Johnson A R, Lipsky P E. Human endothelial cell-T lymphocyte interaction. Endothelial cells function as accessory cells necessary for mitogen-induced $\mathrm{T}$ lymphocyte activation in vitro. $\mathcal{F}$ Clin Invest 1981; 67: 1490-9.

60 Wagner C R, Vetto R M, Burger D R. Subcultured human endothelial cells can function independently as fully competent antigen-presenting cells. Hum Immunol 1985; 13: $33-47$. 
61 Jirik F R, Podor T J, Hirano T, et al. Bacterial lipopolysaccharide and inflammatory mediators augment IL-6 secretion by human endothelial cells. F Immunol 1989; 142: 144-7.

62 Geppert T D, Lipsky P E. Antigen presentation by interferon $\gamma$-treated endothelial cells and fibroblasts: differential ability to function as antigen-presenting cells despite comparable Ia expression. F Immunol 1985; 135: 3750-62.

63 Hughes C C W, Savage C O S, Pober I S. Endothelial cells augment $T$ cell interleukin 2 production by a contactdependent mechanism involving CD2/LFA-3 interaction. f Exp Med 1990; 171: 1453-67.

64 Arend W P, Dayer J-M. Cytokines and cytokine inhibitors or antagonists in rheumatoid arthritis. Arthritis Rheum 1990; 33: 305-15.

65 Hopkins S J, Humphreys M, Jayson M I V. Cytokines in synovial fluid. I The presence of biologically active and immunoreactive IL-1. Clin Exp Immunol 1988; 72: 422-7.

66 Miyasaka N, Sato K, Goto M, et al. Augmented interleukin-1 production and HLA-DR expression in the synovium of rheumatoid arthritis patients. Arthritis Rheum 1988; 31: $480-6$.

67 Buchan G, Barrett K, Turner M, Chantry D, Maini R N, Feldmann $M$. Interleukin-1 and tumour necrosis factor
mRNA expression in rhematoid arthritis: prolonged production of IL1- $\alpha$. Clin Exp Immunol 1988; 73: 449-55.

68 Hirano T, Matsuda T, Turner M, et al. Excessive production of interleukin 6/B cell stimulatory factor- 2 in rheumatoid arthritis. Eur f Immunol 1988; 18: 1797-801.

69 Firestein G S, Zvaifler N J. Peripheral blood and synovial fluid monocyte activation in inflammatory arthritis. II. Low levels of synovial fluid and synovial tissue interferon suggest that $\gamma$-interferon is not the primary macrophage activating factor. Arthritis Rheum 1987; 30: 864-71.

70 Firestein G S, Xu W-D, Townsend $\mathrm{K}$, et al. Cytokines in chronic inflammatory arthritis. I. Failure to detect $\mathrm{T}$ cell lymphokines (interleukin 2 and interleukin 3 ) and presence of macrophage colony-stimulating factor and a novel mast cell growth factor in rheumatoid synovitis. $\mathcal{F} \operatorname{Exp} M e d$ 1988; 168: 1573-86.

71 Buchan G, Barrett $K$, Fujita $T$, Taniguchi $T$, Maini $R$, Feldmann $M$, Detection of activated $T$ cell products in the rheumatoid joint using CDNA probes to interleukin-2, IL-2 receptor and IFN- $\gamma$. Clin Exp Immunol 1988; 71: 295-301.

72 Jackson C J, Garbett P K, Nissen B, Scrieber L. Binding of human endothelium to Ulex Europaeus I-coated Dynabeads: application to the isolation of microvascular endothelium application to the isolation 